\title{
The Defects of Anti-corruption Literature since 1990 and Revelation of the Legal Awareness in China
}

\author{
Han Ruihui ${ }^{1}$ \\ ${ }^{1}$ Humanities School, Jinan University, Zhuhai, Guangdong Province, China \\ Correspondence: Han Ruihui, Humanities School, Jinan University, Zhuhai, Guangdong Province, China. E-mail: \\ hanruihuihh@hotmail.com
}

Received: April 21, 2014 Accepted: May 5, 2014 Online Published: May 28, 2014

doi:10.5539/jpl.v7n2p150 URL: http://dx.doi.org/10.5539/jpl.v7n2p150

\begin{abstract}
Anti-corruption literature sprouted up and prospered in China ever since 1990s, and such literature has significant meaning for the governmental fight against corruption. Anti-corruption literature is very popular and has great influence in Chinese readers. However, the analysis of such kind of literature reveals the defects in artistic form and subject content despite the superficial stories of it cater the taste of the readers. The defects are caused by the traditional thought mode and habit, especially the consciousness of ruling by the upright officers and the officialdom thought. The cultural background of China facilitates the birth and prosperity of anti-corruption literature, but at the same time it results in the defects of anti-corruption literature. For almost both the readers and writers, the legal awareness is lacked of, and the lack of it is not only one factor of corruption in reality, but also one cause of the defects of the Chinese anti-corruption literature since 1990. From the defects one can get the revelation of the legal awareness in China.
\end{abstract}

Keywords: anti-corruption literature, consciousness of ruling by upright officers, legal awareness, officialdom thought

\section{Introduction}

In recent years, especially after 1990s, the anti-corruption novel is a new Literature perspective in China. Some anti-corruption novels such as Institution Courtyard, The way to Promotion, Power Fair, etc are the best-sellers. The special counters are set for such novels in many bookstores. In the field of anti-corruption Literature, the most famous writers are Lu Tianming, Zhou Meisen and Wang Yuewen. Their works Mading in China, The Blue Sky, Traceless Snow, Highest Benefit, and No Stories in Official Circles have great popularity in the group of Chinese readers. The readers of anti-corruption novels are mainly male, especially the civil servants.

Undoubtedly, the anti-corruption literature is the bright scenery line and the best-seller in the reader group. Lots of anti-corruption literature appears in the form of popular novels and net literature. The pursuit for profit fuels the writing and Publishing of such novels, even some of the novels are second-rate or shoddy. The writers of them lack of the deep thought, and the opinions of the novels are backward, for example, they emphasize the rule of men but not the rule of law. Rule of men is one of the deep-rooted bad habits of Chinese traditional culture. Such writers do not put forward the progressive point of view, and the novels appeal to the traditional thinking mode. As a result, the themes of the novels are vulgar. The paper analyzes the phenomenon in the following.

\section{Literature Review}

According to the searching result in China National Knowledge Infrastructure (CNKI), the earliest papers on anti-corruption literature appeared in the later 1990s. The papers believed the anti-corruption literature had important meaning as a way for anti-corruption in reality. The papers published from 1998 to 2003 commonly held that view. From 2004, some papers began to analyse the artistic features, holding the view that the anti-corruption novels did not get artistic achievement, although their themes caught the attention of the readers.

From 2005 to 2010, there were several $\mathrm{PhD}$ and master theses focus on the anti-corruption literature. For example, the master thesis The Ethical Examination on Anti-corruption Novels discussed the moral consciousness of anti-corruption novels, believing such novels had the feature of promoting the desire for power and sex, and the morality of such novels needed to be refined. (Long, 2009) Some researchers discussed the anti-corruption novels through the perspective of traditional culture, such as Dong Bin's The Cultural Meaning 
and Value of Anti-corruption Novels: The Interdisciplinary Study of Law and Literature in the Perspective of Culture. (Dong, 2007)) From 2011 until now, some papers began to sum up the features of anti-corruption Literature. For example, the master thesis The Study of Expressive Style of the Anti-corruption Novels Since 1990s defined the concept of anti-corruption novel and combed the study materials on anti-corruption literature. $(\mathrm{Wu}, 2010)$

By combing the topics of the papers since 1998, it would find that the study of anti-corruption literature study could be divided into three aspects: First, the realistic meaning of anti-corruption literature, for example, the paper Fatal Decision: the Anti-corruption Strength of Literature analyzes the plot of novel Fatal Decision and considers the anti-corruption literature has the function of anti-corruption in reality. (Ji, 2000). The paper The Hidden Value of Anti-corruption Literature: calling for the Institutional Innovation believes that the anti-corruption novels, whose authors are comprised by the amateur writers who have the experience of being officials and the professional writers, has the hidden value of calling for the institutional innovation. (Song, J.,2008) Second, the features of anti-corruption literature. For example, the paper The Problem of Anti-corruption Literature: The Intertwining of Anti-corruption Literature and Officialdom Literature discusses the features of anti-corruption literature through comparing the anti-corruption literature and the officialdom literature. (Shao, 2006) Third, interdisciplinary analysis on anti-corruption literature, such as the analysis in the perspective of culture and ethics. For example, the paper The Anti-corruption Literature in the Perspective of Mass Culture analyzes the characteristics of anti-corruption Literature in the perspective of mass culture, and belives the anti-corruption literature satisfies the emotional need and caters the aesthetic taste of the readers. (Pan, 2003)

As a kind of very popular literature, anti-corruption literature has the problems of traditional thinking and catering the vulgar taste of the readers. Previous study analysed the phenomenon in some aspects, but it still calls for more in-depth discussion and analysis, because the phenomenon is intertwined with the traditional culture and contemporary situation of China, especially the legal awareness of the ordinary writers and readers.

\section{The Origin and Features of Anti-corruption Literature}

\subsection{The Origin of Anti-corruption Literature}

In the perspective of social environment, anti-corruption literature is the corollary of officialdom thought and the power worship. There was strong officialdom thought in history, which was embodied in the ancient Chinese novels, dramas and poems. In the description of such literature works, the unjust charges were not diminished by the legal procedure, but by the bribery. The officialdom thought still existed in the world of ghosts and gods, and religion, which was imaged by Chinese. In the gods of Buddhism, there were strict grades, and the success depended on the bribery and the relationship.

The historical officialdom thought still influences the modern China. The public functionary examination becomes hotter and hotter, with the more and more applications for such examination year by year. In view of many Chinese, once one is enrolled as civil servant, he or she would has the "iron rice bowl" regardless of what his or her performance in work. On the other hand, in the eyes of some examinees, some civil-service institutions are the power units, and being enrolled by such institutions means getting some privileges. So in recent years, civil service is the favorite job for the young people.

The public abominates the corruption of the administrative system, although they are keen for the job of civil service. In ancient history, the public were opposite to the government. In contemporary China, the phenomenon of corruption became more and more obvious, so the public distrusted some governments more and more. As a result, the public longed for the incorrupt officers and governments, and that becomes a realistic cause of popularity of anti-corruption literature. "Anti-corruption literature would exist and develop as long as the corruption is not eliminated.” (Xu, 2010)

In the perspective of technology, network is the significant factor for the creation of anti-corruption works. The transparency propagation is reinforced by network, with the wider spread and faster speed. This causes some sensitive topics, such as the ethical conduct of the government, becomes the focus of the public. The mainly users of network in China is the grassroots young people, who have predominance in the network world. On the other side, the 180 degrees effect, which means the function of overturning the mainstream speech of the real world in the network, makes the elite class become the vulnerable group, and the grass-roots have a powerful say. Once the sensitive topics are inspired in the network, they would soon become the focus of the public, and the corruption in the official circle would attract the most attention.

In the perspective of the readers, the privacy of the official circle, the deal with power, money and sex, the 
extramarital affair of the officers, which exposed by the anti-corruption literature, all are the sensitive topics for the readers. With the good sale, as a kind of popular realism literature, the anti-corruption literature is the favorite writing forms for many writers. The world represented by the anti-corruption literature, which featured by distinguishing the good from the bad and the plot of reaping what one sows, conforms to the aesthetic taste of Chinese readers. Ancient Chinese works such as Liaozhaizhiyi and the Midsummer Snow, all have such kind of plot structure, which was formed in the long cultural history.

In the perspective of current political environment of contemporary China, anti-corruption is a serious concern of central government and an important task of all levels of government. The frequent exposing of corruption by mainstream media makes the corruption attract the attention of the public, and the anti-corruption literature therefore becomes popular.

\subsection{The Features of Anti-corruption Literature}

First, realism is the artistic form of anti-corruption literature, which lets the readers discover the corruption of the official circle, and is the guide for anti-corruption and has significant meaning for the governmental anti-corruption work. The writers of anti-corruption literature become more and more, among them are professional writers, the separating employees from the civil service. The writers, who have officialdom experience, show more realism characteristics in their writing. Their novels provide samples for the anti-corruption of the government. The government ramps up more effort to fight the corruption, and publication, film and television management structure encourages the creation of anti-corruption works, and all those promote the anti-corruption literature to a great extent.

Second, the content of the anti-corruption literature has a critical role. It is not a kind of literature sings the praises for the government, but literature of exposure. Since 1949 to 1966, most of the literature works belongs to the former. But the present anti-corruption literature criticizes the corrupt and unscrupulous officers, reveals their villainous souls and disastrous crimes. The most frequent phenomenon that the anti-corruption literature reveals is collusion between government and business, which shows the history of the prosperity of businessmen is the history of bribery of the officers. The officialdom thought is also one target of anti-corruption literature criticism. In the literature works, for the corrupt officials, position is the most important part of their lives. Their position in the official circle determines their status and well-being. In order to be promoted, they would try by hook or by crook, even sacrifice the national economy and the benefit of the people.

The ending of the anti-corruption novels is often about the self-destruction of the corrupt officials who has done so many injustice things and the final victories of the upright officers. From the perspective of the plot model, it would find that the anti-corruption novels are the works which celebrate the mainstream themes. Even when such works expose and discover the dark side of the official circle, they are always according to the mainstream theme. The cause of such situation is related to the encouragement of the published sector, and also related with the happy ending model of story-telling in Chinese tradition. The literary archetype of honest and upright officers in Chinese literature history plays an important role in such novels.

Such features of anti-corruption literature are different from the satirical novels about official circle in later-Qing dynasty. The satirical novels about official circle believed the society was ramshackle and beyond reform, so they put up with the collapsing therapy straightforward, which meaned breaking down the administration and getting it be reconstructed. But the anti-corruption novels are encouraged by the government and criticize the dark side with the fine hope for the future.

Third, in the perspective of the taste of the readers, the anti-corruption novels have the effect of emotional comforting for the readers. Corruption is a sensitive topic in China, the public hate bitterly the corruption, so the anti-corruption novels have the effect of emotional comforting for the readers. The world anti-corruption novels represented caters the taste of the readers and has the broad market, with the black-or-white protagonists and the simple plots of conflict. Both the readers and writers would enjoy the narrative of the stories of the good or bad protagonists, but they seldom investigate deeply the nature of human being and the legal awareness in the anti-corruption stories.

\section{The Defects of Anti-corruption Literature}

A comprehensive study of the anti-corruption literature from 1990s would discover the serious defects of it in the artistic form and subject content, although the anti-corruption literature becomes very popular in recent years.

\subsection{Defects in Artistic Form}

First, the protagonists in anti-corruption novels are often stereotypical and "white or black". For example, if one is the corrupt official, he or she would be without humanity, lustful and greedy. Description of the corrupt 
officials focuses on two aspects: sex and money. Taking the description of sex in Wealth and Humanity for example, the corrupt official Meng Guangtai cannot remember how many women he has had affairs with: "There are the undergraduates postgraduates; the 18 years old girls and the charming ladies; the black girls of Southeast Asia and the white women..." (Bi, 2000b) In the novel Highest Benefit, the businesswoman Zhao Juanjuan seduces the officers at all levels shamelessly in order to win the case, and Chen Zhonglian, a corrupt official, makes his new wife be the mistress of the party secretary of the city for his own promotion.

There also the examples of the description of money. In The Blue Sky, the major who presents the gift to the vice-governor feels awkward and even dare not get into the house of the vice-governor, because he thinks his present, a marten coat which is worth almost a million Yuan, is too shabby compared to the gifts others presents to the vice-governor. In The Choice, the state-owned enterprise, Zhongyang Textile Group, is beset with troubles internally and externally, and the workers of the enterprise are unemployed and badly off. At the same time, the leading group of the enterprise bribes the vice secretary of the province and director general of the anti-corruption bureau with several million Yuan. In The Trackless Heavy Snow, the chief of the state-owned enterprise gives numerous shares to the leaders in power, as a result, the new acting major shoots the secretary of the government dead in order to keep the secret.

The descriptions mentioned above has the realistic reason. In China, sex is a way to demean, for example, the extramarital sex is a serious moral problem, which would influence the official career. Many corrupt officials' sexual scandals would be disclosed in the news after they are arrested in reality. So in the novels, the writers would describe such affairs. Chinese modern writer Zhang Ailing said: "Power is the best philter." The narrative appears in such novels is the representation of the reality. In the anti-corruption novels, the male officer (often the corrupt officials) is the symbol of the power, but the female protagonist is often seemed as the existence of sex. In the adultery relationship for money or power, the male and female protagonists rarely have the real emotional contact, and the only they have is the relationship of interavailability.

The corrupt officials would try to gain the economic benefit after they get the power. In the opinion of the corrupt officials, "Controlling the others is easily be deemed as a way to realize all kinds of goals. Power is the commonly used tool, even better than money, because the power can manipulate the money. " (Wrong, 2001) In ancient China, the government lacked of the strict supervisory organization, so the power-for-money deal was inevitable. The desire of human being is boundless, although many officials had the high salary, but the corruption still happened, and the power was still the tool for the individual economic benefit.

The power-for-money deal or the power-for-sex deal is the representation of the reality to some extent. However, the problem is that the description of the upright officers and the corrupt officials is extreme and one-sided. For example, in such novels, the corrupt official can give his new wife to his superior for money and power; the upright officer can sacrifice his mother, wife and daughters for the justice. That obviously does not conform to the logic of humanity. In Wealth and Humanity writer describes the chief procurator:

"Procurator Gao's home is compromised by three rooms and one hall, which is of the oldest kind of apartment, and there is only one corridor to pile up the clothes and books. The entire apartment is no more than 70 square metres. One room belongs his mother and father, and one room for his two daughters. His wife and he live in another room. In the small hall, there is a little dining-table and a 14 inches black-and-white television. His wife lay in bed with a sallow face." (Bi, 2000a)

In The Angry of the Heaven, the writer describes the upright section chief as following:

"Chen Hu's single apartment is very narrow. The hall is little, in fact, it is only a corridor of three square metres, and the washing machine and bicycle are there. The bedroom is used as not only the study room, but also the dining-room. Three bookshelves, one chest of drawers and one single bed, one large-size secretaire occupies almost all the room. An oil-painting frame stands on the ground of the room, the paint and pallet scattering here and there...Only one shabby sofa is beside the oil-painting frame."(Fang, 1996)

Except such kind of description, the plot of the such novels would also be extreme. For example, the upright officer would be framed up by others, or be so poverty-stricken that he has no money to treat the diseases of his wife and daughters. When he begins to forsake his wife and daughter to fight against the corrupt officials to death, the plot of the novel would suddenly have a changeover with an incident. At last, the corrupt officials are arrested and get what they deserved. The upright officer would then get the understanding of others and be saved from death. In short, "After reading many anti-corruption novels, you would find that the 'anti-corruption hero' equals the resoluteness in work and being misunderstand and frustration in life.”(Liu, 2004) 
Readers would find the description and plot of the novels do not conformed to the normal humanity. Normal humanity would have the seven emotions and six sensory pleasures, but the upright officers in such novels have the steel like will even they can sacrifice anything without hesitation, which is abnormal. That makes people easily associate with the perfect protagonists appeared in the Cultural Revolution literature, which were inflexible and stiff, although they had not any shortcoming by the standards of revolution. The readers can get the feeling comfort from the anti-corruption literature, but such novels simplify the plot and make the characters as sterotype.

Through the above discussion, one would find that the anti-corruption novels in recent years are of monotonous pattern and too simple content. "The contemporary anti-corruption literature works have the similar plot and characters."(Zheng, 2006) Even when the readers read the beginning of the novels, they would know the ending of them. However, the anti-corruption novels are very popular despite the obvious shortcomings of them.

\subsection{Defects of the Creation Themes}

The anti-corruption literature has the tendency of catering the vulgar taste of the readers, because such works pursuit the read frequency and book salesman volume. The taste of the readers is important for the writers. "There is obvious tendency of pan-politicalization in anti-corruption novels. They do not care the deep analysis of the theme, and rest only on the representation of the real life. They please the readers by the advantage of theme and documentary features, so someone epitomize the phenomenon as news-telling." (Yang, 2002). That the anti-corruption novels include the sex scene deliberately in order to increase the watching focus is a frequently-used tool.

In order to get large salesman volume, many anti-corruption novels are so vulgar, full of the plot of the fists and pillows, that they become the erotic literature. Such so-called anti-corruption novels are filled with the plots of the ignorant corrupt officials who triumph prey upon the female, even the condition is more serious than that in the officially forbidden erotic literature. There also some other anti-corruption novels introduce the dark side and the tactics of the official circle, which is suspected of instigating the corruption and have very bad influence.

In addition to the defect mentioned above, the anti-corruption literature has the obvious consciousness of ruling of the upright officers, which means the public hope the justice could be achieved by the ruling of the upright officers. In the anti-corruption novels, the writers often focus on some upright officers, and the plots are often about that the corruption problems are all solved by the struggle of such upright officers. "In reality, executing several corrupt officials cannot crack down the corruption thoroughly. In the works of the anti-corruption literature, singing praise songs for several upright officers cannot guarantee the lasting political stability and prosperity of the society. The anti-corruption literature works should reflect on the consciousness of ruling by upright officers seriously and propagate the positive spiritual value. It is not practical to achieve a purified government by praising the upright officers. What the excessive propagating of the consciousness of ruling by upright officers implies is the inability and frustration of the social institution, and such consciousness is backward." (Li, 2007) The consciousness of ruling by upright officers is not beneficial to the legal construction of China.

The consciousness of ruling by upright officers has an objective necessity. First, it related to the history of ruling by man but not legal system. In the Confucianism which plays the leading role in Chinese culture, "Confucius struggled to propagate a kind of idealist spirit and requested every individual, bachelor can exceed his own advantages and disadvantages to foster simple and honest solicitude for all society." (Yu, 1987) The successors of Confucianism intensify constantly such orthodox consciousness of concerning first and to enjoying themselves last.

The anti-corruption novels are similar to the detective novels in the content, because such novels focus on the individual function and the image of the upright officer becomes most obvious. That the description of the upright officer in the novels conforms to the expectation of the public is one reason for the plot model. There were lots of such literary figures in Chinese history, such as Baogong, Hairui, etc, and they were mentioned constantly in folk. Contemporary anti-corruption literature inherits and reinforced the literature tradition. The consciousness of ruling by upright officers roots deeply in the custom and collective thinking model, although the situation has be changed to large extent by enforcement of the legal system. The lack of legal awareness is still popular in some groups.

"The ordinary people, especially the ordinary peasants did not get well education, or they were educated by the rulers for easy manipulation. Their political expectation was the hoping for the wise king, capable prime minister, and the upright officers, which followed the clue of ruling by men thought. But the reality always brought the heartbreaking disappointment to them." (Wang, 1981) Although such beautiful hope cannot be realized in the 
real world, it is realized in the content of the anti-corruption literature. Some writers believe that "in the current situation without effective restriction mechanism, the individual virtue of the cadres plays a critical role." (Zhang, 2007)

The consciousness of ruling by upright officers causes the strong story of the anti-corruption novels, but the depth of characters analysis is not enough. In such literature works, the protagonists is white-or-black: corrupt officials or upright officers. The contrast of the two kinds of characters is the most important feature of anti-corruption novels. The happy ending depends on the struggle of the upright officers. The plot model is the continuity of the ancient literary archetype of ruling of the upright officers. In ancient novels or dramas, the upright officers always discovered and correted the unjust cases in the end, no matter how miserable the protagnists were in the works. For example, the dramas Midsummer Snow and Qing Xianglian told the stories about the unfortunate women because of the rich and heartless characters, but at the end of the dramas, the upright officers would come out and helped them to defeat the bad characters. In the two dramas, they were Doue's father and Baogong respectively, all were upright officers. However, in the western literature works of such kind story, the writers would focus on the analysis of the humanity, and they have more legal awareness. As in Shakespeare's dramas, the origin of the tragedies was the evil of human nature. There was no happy ending and the consciousness of ruling by upright officers in Shakespeare's tragedies. Upright officers were not the important protagonists in his dramas. The focus in Shakespeare's works was the nature of human being, which was different from that in ancient Chinese dramas. Analysis of human nature is lacked in the current anti-corruption literature works, and that is a defect of such works. In such works, the readers get many superficial stories but can rarely harvest the deep analysis of human nature. The strifes openly and secretly the novels represent are superficial, which cannot provide the deep analysis of human nature, so someone lists the anti-corruption novels as detective novels.

When the readers read the anti-corruption novels, they often get such impression: the corrupt official is the rascal, who depends on nothing but a powerful backer. Once the lust for money, beauty and power is pulled out from their spiritual world, their spiritual world would become empty. The only rival of the corrupt official is the upright officer, and the upright officer always wins in the end. Human nature is complicated, as the anti-corruption novels describe only one aspect of the corrupt official character. It is also profound, but the narrative of such novels is confined to the superficiality, which cannot reveal the deep reason of the action. The writers focus on the narrative of the action, but seldom reflect on the legal culture in China, because the writers rarely have some legal awareness.

\section{Conclusion}

Anti-corruption literature is the prosperous kind of literature in China ever since 1990s. Because of the existence of officialdom thought in the history of China, the ruling of the upright officers is the literary archetype in China, which conforms to the taste of Chinese readers in the cultural background. Once the anti-corruption literature came out, it caught the attention of the readers, even the popularity of anti-corruption literature caused many times of piracy.

Numerous writers create the anti-corruption novels because of the popularity of it, and different writers represent the dark side of the official circle from the different perspective, which has great meaning for the anti-corruption work for the government. There are some excellent works such as The Humble Abode, which was filmed as a TV series. However, most of the anti-corruption literatures have many defects, one of which is the lack of legal awareness.

The creation of anti-corruption literature cannot break away from the influence of traditional thought mode and habit, especially the consciousness of ruling by the upright officials. That causes the monotonousness of artistic form and the defective thought in the subject content.

The power pattern in which the emperor is on the top was formed in the feudal age of China, which lacks the supervisory system. Although there were the emperors who fought against the corruption by the draconian laws, the phenomenon of corruption repeated because of the lack of effective supervision. All those stimulate the emergence of anti-corruption literature. However, the artistic form and subject content of such anti-corruption literature are defective because of the influence of backward officialdom thought and the lack of legal awareness.

\section{References}

Bi, S. (2000a). Wealth and Humanity (p. 151). Jiangsu Art Publishing House.

Bi, S. (2000b). Wealth and Humanity (p. 442). Jiangsu Art Publishing House.

Dong, B. (2007). The Cultural Meaning and Value of Anti-corruption Novels: The Interdisciplinary Study of Law 
and Literature in the Perspective of Culture ( $\mathrm{PhD}$ Thesis). Lanzhou University.

Fang, W. (1996). The Angry of the Heaven (p. 226). Yuanfang Publishing House

Ji, C. (2000). Fatal Decision: The Anti-corruption Strength of Literature. Special Economic Zones Outlook, (6), 45.

Li, X. (2007). Consciousness of Ruling of the upright officers: The Double-edged Sword in Literature Creation. Journal of Henan Radio \& TV University, (3), 58-59.

Liu, Y. (2004). The Patterning Tendency of the Positive Characters in Anti-corruption Literature. Social Science Review, (5), 150-151.

Long, J. (2009). The Ethical Examination on Anti-corruption Novels (Master Thesis). Hunan Normal University

Pan, X. (2003). The Anti-corruption Literature in the Perspective of Mass Culture. Shandong Social Science, (1), 92-94.

Shao, G. (2006). The Intertwining of Anti-corruption Literature and Officialdom Literature. Journal of Ningxia University, (2), 77-79.

Song, J. (2008). The Hidden Value of Anti-corruption Literature: Calling for the Institutional Innovation. Jinan: International Academic Conference on the Chinese New Period Literature of 30 Years and the $15^{\text {th }}$ Chinese Contemporary Literature Conference. October 24.

Wang, Y. (1981). The Study of Chinese Bureaucracy (p. 45). China Social Sciences Publishing House.

Wrong, D. H. (2001). Power: Its Forms, Bases, and Uses (p. 262). Beijing: China Social Sciences Press.

Wu, Z. (2010). The Study of Expressive Style of the Anti-corruption Novels Since 1990s (Master Thesis). Guangdong Polytechnic Normal University.

$\mathrm{Xu}, \mathrm{G}$. (2010). On the Main Cause of the Development of Contemporary Anti-corruption Literature. Literature of Times, (3), 22-23.

Yang, J. (2002). News-telling: The Aesthetic Misunderstanding of Current anti-corruption Novels. Journal of Novel Criticism, (5), 33-38.

Yu, Y. (1987). Scholar and Chinese Culture (p. 35). Shanghai: Shanghai People's Publishing House.

Zhang, P. (2007). I Wrote "The Choice". Journal of People Forum, (9), 57.

Zheng, Y. (2006). The Cool Thought about the Popularity of Anti-corruption Literature. Theory Circle, (6), 182-183.

\section{Copyrights}

Copyright for this article is retained by the author(s), with first publication rights granted to the journal.

This is an open-access article distributed under the terms and conditions of the Creative Commons Attribution license (http://creativecommons.org/licenses/by/3.0/). 